\title{
Effects of Wnt/ $\beta$-catenin signaling on bisphenol A exposure in male mouse reproductive cells
}

\author{
ZHIQI FANG ${ }^{1}$, XIAOLI LIU ${ }^{2}$, XIAOSI YANG ${ }^{2}$, XIANBIN SONG ${ }^{2}$ and XIAOYU CHEN ${ }^{2}$ \\ ${ }^{1}$ Department of Urology, The Third People's Hospital in Hefei, Anhui Medical University, Hefei, Anhui 230022; \\ ${ }^{2}$ Department of Histology and Embryology, Anhui Medical University, Hefei, Anhui 230032, P.R. China
}

Received September 22, 2014; Accepted June 15, 2015

DOI: $10.3892 / \mathrm{mmr} .2015 .4028$

\begin{abstract}
Bisphenol A (BPA) is a chemical used in numerous consumer products that is able to interfere with the mammalian endocrine system. The aim of the present study was to investigate the effects of BPA on male mouse reproductive cells following prenatal to postnatal exposure. In addition, the influence of BPA was detected on the expression levels of $\beta$-catenin and dickkopf WNT signaling pathway inhibitor 1 (DKK-1) during the differentiation of spermatogenic cells in the mouse testes. $\beta$-catenin and DKK-1 are two important proteins of the $\mathrm{Wnt} / \beta$-catenin signaling pathway. On gestational day 1, pregnant ICR mice were randomly divided into four groups: A dimethyl sulfoxide group, and three groups treated with various concentrations of BPA $(0.5$, 10 , and $50 \mu \mathrm{g} / \mathrm{kg}$ ). BPA was administered from gestational day 1 to weaning on postnatal day (PND) 42. The number of murine pups and the male:female ratio was recorded for each group. On PND 42, the male pups were sacrificed and their wet weights and testicular coefficients were measured. Immunohistochemical and western blot analyses were used to detect the protein expression of $\beta$-catenin and DKK- 1 in the testicular tissue samples of the six-week-old male mice. The results indicated that the number of murine pups, as well as the testicular viscera coefficient of the male mice, significantly decreased in the BPA-treated groups, as compared with the control group $(\mathrm{P}<0.05, \mathrm{P}<0.01)$; however, no significant difference was observed in the male/female ratio in the BPA-treated groups, as compared with the control group $(\mathrm{P}>0.05)$. The results from the immunohistochemical and western blot analyses indicated that the protein expression of $\beta$-catenin and DKK-1 were significantly increased in the BPA-treated groups, as compared with the control group, and the distribution of spermospore and Leydig cells also increased in the testes.
\end{abstract}

Correspondence to: Professor Xiaoyu Chen, Department of Histology and Embryology, Anhui Medical University, 81 Meishan Road, Hefei, Anhui 230032, P.R. China

E-mail: cxyayd@163.com

Key words: bisphenol A, testicular germ cell, $\beta$-catenin protein, DKK-1 protein
These results suggest that high expression levels of $\beta$-catenin and DKK-1 may participate in BPA-induced pathogenesis in male mouse reproductive cells.

\section{Introduction}

Bisphenol A (BPA) is an environmental endocrine-disrupting compound (EDC) that is widely used in polycarbonate plastics, including hard plastic bottles, water pipes, toys, metal-based food and beverage cans, medical materials, dental sealants, and building materials (1-4). Exposure to EDCs has become a major concern for mammalian development, due to the common daily exposure of mammals to BPA-contaminated food and water. Furthermore, BPA may be released from these industrial products by various physical or chemical processes. The released BPA may then either be inhaled as dust, or absorbed through the skin. As determined by random sampling, detectable BPA was shown to be present in $>90 \%$ of human urine samples (5). Due to this prevalence, the adverse health effects of BPA have been investigated in numerous studies (6). Estrogen has a major role in female reproduction; however, evidence suggests that estrogen is also involved in the development and function of male reproductive organs (7). BPA has been detected in maternal blood, saliva and placental tissue samples (8), and may cause the abnormal functioning of germ cells. Prenatal exposure to BPA in mice has been demonstrated to reduce the efficiency of sperm production and to affect the development of reproductive organs in male pups (9). In addition, previous studies have demonstrated that BPA exposure results in lifelong adverse effects on the male reproductive system in rodents, as a consequence of neonatal exposure to potent estrogens (8-10). In rats, reproductive capability and gonad development (11), androgen action (12), spermatogenesis efficiency and Sertoli cell number (13), as well as abnormalities of the reproductive tract (14), were induced by neonatal exposure to estrogens. The disruptive effects of potent estrogens (such as diethylstilbestrol) may also occur in adulthood following normal pubertal development (8).

BPA may disrupt the endocrine system via various mechanisms. Kabuto et al (14) demonstrated that exposure to BPA during embryonic/fetal development and infancy induced tissue oxidative stress and peroxidation, ultimately leading to underdevelopment of the brain, kidney and testes. The function of organs and/or systems may be modulated by exposure 
to environmental chemicals that interfere with signaling molecules (15). The Wnt/ $\beta$-catenin signaling pathway has an important role in the development and regulation of cell growth. The Wnt/ $\beta$-catenin signaling pathway is predominantly composed of Wnt, Wnt receptor proteins, $\beta$-catenin, and the T-cell factor/lymphoid enhancer factor-1 family (Tcf/Lef) transcription factors, along with their downstream target genes $(16,17)$. To date, few studies have reported the effects of BPA on the reproductive system of male mouse pups and the Wnt/ $\beta$-catenin signaling pathway. The present study evaluated the toxicological effects of BPA exposure on the reproductive system by observing morphological changes in ICR male mouse pup testes. In addition, the effects of the Wnt/ $\beta$-catenin signaling pathway on the embryonic development of BPA-treated mice were investigated in order to clarify the molecular mechanism underlying the effects of BPA, and in order to provide a theoretical basis for treatment strategies.

\section{Materials and methods}

Chemicals and instruments. BPA (99\% purity; Sigma-Aldrich, St Louis, MO, USA) was dissolved in saline containing dimethyl sulfoxide (DMSO; Shanghai Chemical Reagent Co., Ltd., Shanghai, China), with a DMSO concentration $<0.01 \%$, in order to obtain the selected doses. Rabbit anti-mouse $\beta$-catenin (cat. no. sc-7199), and anti-dickkopf WNT signaling pathway inhibitor 1 (DKK-1; cat. no. sc-25516) monoclonal antibodies were purchased from Santa Cruz Biotechnology, Inc. (Dallas, TX, USA), and the Secondary Antibody Immunohistochemistry kit (biotinylated horse anti-mouse IgG; 1:200 dilution) was purchased from OriGene Technologies, Inc. (Beijing, China). The TSJ-1A Automatic Organizations Dehydration machine was purchased from Tianli Aviation Electrical Co., Ltd. (Tianjin, China), and the RM2135 Leica Paraffin Slicing machine was from Leica Microsystems (Wetzlar, Germany). The BM-II Pathological Tissue Embedding machine was purchased from the Electric Power Research Institute (Anhui, China), and the Nikon 80 I Biological Microscopic Imaging and Analysis system from Nikon Corporation (Tokyo, Japan).

Animals and experimental design. All animal procedures were approved by the Institutional Animal Care and Use Committee of Anhui Medical University (Hefei, China). A total of 60 female and 30 male 9-week-old ICR mice were obtained from the Animal Center of Anhui Province (Hefei, China) and housed at $25^{\circ} \mathrm{C}$ in conventional polystyrene cages in a $12 \mathrm{~h}$ light/dark cycle. The mice were provided a rodent diet and high purity water (reverse osmosis filtered) provided in glass water bottles ad libitum. The mice were allowed to acclimatize to the housing conditions for one week prior to being placed in a cage (male:female, 2:1) at 9:00 pm, and checked the following morning at 7:00 am. Mating was confirmed by the presence of a vaginal plug, which is a well-known sign of pregnancy. Once the vaginal plug was observed, the pregnant mice were separated from the males and individually caged. The day the vaginal plug was detected was defined as gestation day (GD) 1. On GD 1, the confirmed pregnant females (40 dams in total) were randomly divided into four treatment groups (10 dams per group): A solvent control group, which was orally treated with DMSO, and three groups, which were treated with $0.5,10$, or $50 \mu \mathrm{g} / \mathrm{kg} /$ day BPA. The mice were treated with BPA by placing a pipette tip of their mother's milk containing the dosing solution into the mouth once a day from GD 1 to postnatal day (PND) 42. To maintain the BPA concentration, the dose was changed every 2-3 days with the growth of weight. The number of offspring produced by each pregnant mouse, the male:female ratio in each group, and the testis coefficient were subsequently counted.

Specimens and immunohistochemistry. A total of 10 randomly chosen male pups were assigned for staining on PND 42. The male pups were initially weighed, prior to being anesthetized by intraperitoneal administration of 1\% $0.1-0.2 \mathrm{ml}$ sodium pentobarbital (Sigma-Aldrich) and sacrificed immediately by exsanguination, and the abdominal cavity was then rapidly opened and testis tissue samples were harvested. The testis tissue was subsequently weighed and the organ coefficients were calculated (testicular organ coefficient $=$ weight of mice / wet weight of testis). One side (left) of the testicular tissue sample was fixed in $10 \%$ neutral formalin ( $\mathrm{pH} 7.2-7.4)$ for $24 \mathrm{~h}$ at room temperature and rinsed in running water overnight, prior to being embedded in paraffin. Each testis tissue sample was cut into $5 \mu \mathrm{m}$ sections and mounted onto a glass slide, and every 5th section of the testis tissue sample was developmentally evaluated by counting the number of germ cells, which were positively stained with hematoxylin and eosin (HE; Beyotime Institute of Biotechnology, Haimen, China). All sections were evaluated by an observer who had no knowledge of the treatment groups. The number of germ cells present in a subset of sections was confirmed by another observer who also had no knowledge of the treatment groups. The remaining sections were immunostained as previously described (18). Immunohistochemistry was performed on the paraffin-embedded mouse testes on PND 42, using antibodies targeting $\beta$-catenin (1:200 dilution) and DKK-1 (1:100 dilution). The nuclei were stained with hematoxylin. The stained sections were then observed under a microscope (Nikon Corporation). Immunohistochemical analysis was performed on the testes of the male mice from each group, and the $\beta$-catenin and DKK-1-positive cells were counted using a Biological Microscopic Imaging and Analysis system (Nikon Corporation). The number of cells exhibiting positive $\beta$-catenin and DKK-1 expression in each section was recorded for statistical analysis.

Quantification of the molecules involved in the Wnt/ $\beta$-catenin pathway. The protein expression levels of $\beta$-catenin and DKK-1 were analyzed by western blotting. The remaining side (right) of the testicular tissue samples of the male mice were removed. Under sterile conditions, the testicular tissue samples were weighed. The cell lysates were sonicated for $5 \mathrm{~min}$ on ice and centrifuged at 7,500 x g for $10 \mathrm{~min}$ to sediment the particulate material. The testicular tissue samples were homogenized and the protein concentration of the supernatant was subsequently quantified using a bicinchoninic acid assay kit (Beyotime Institute of Biotechnology). Following normalization to a similar protein concentration, the samples and marker (10-230 kDa) (New England Biolabs Inc., Ipswich, MA, USA) were concentrated, and $50 \mu \mathrm{g}$ protein was separated 
by 5 and $12 \%$ SDS-PAGE, prior to being transferred to nitrocellulose membranes (EMD Millipore, Billerica, MA, USA), and incubated with the following primary antibodies: Rabbit anti-mouse $\beta$-catenin antiserum (1:2,000 dilution), anti-DKK-1 monoclonal antiserum (1:1,500 dilution) and anti- $\beta$-actin (1:5,000 dilution; cat. no. sc-47778, Santa Cruz Biotechnology, Inc., Dallas, TX, USA) for $1 \mathrm{~h}$ at room temperature, and then at $4^{\circ} \mathrm{C}$ overnight. The membranes were subsequently washed three times with tris-buffered saline containing Tween 20, and then incubated with a horseradish peroxidase-conjugated secondary antibody (Santa Cruz Biotechnology, Inc.) for $2 \mathrm{~h}$ at room temperature. The immunoreactive bands were visualized using an Enhanced Chemiluminescence Reagent Western Blot Detection system (Pierce Biotechnology, Inc., Rockford, IL, USA). The protein expression levels were quantified with $\beta$-actin as an internal control using Image-Pro Plus 6.0 image analysis software (Media Cybernetics, Inc., Rockville, MD, USA).

Statistical analysis. All statistical data were expressed as the mean \pm standard deviation. SPSS 17.0 statistical software (SPSS, Inc., Chicago, IL, USA) was used for statistical analysis. Statistical analysis was performed by one-way analysis of variance. $\mathrm{P}<0.05$ was considered to indicate a statistically significant difference.

\section{Results}

Effects of BPA on murine reproduction and development. In order to determine the effects of BPA on spermatogenesis, testis development was evaluated in the mice treated with BPA for 42 days. The number of offspring in the ICR pregnant mice was significantly lower (7-12/litter) in the 10 and $50 \mu \mathrm{g} / \mathrm{kg} /$ day BPA-treated pregnant mice, as compared with the vehicle control group $(\mathrm{P}<0.05$, Fig. 1A). However, no statistically significant difference was observed in the male:female ratio of the BPA-exposed pregnant mice, as compared with the vehicle control group ( $\mathrm{P}>0.05$, Fig. 1B). With increasing BPA dosage, the testicular viscera coefficient of the BPA-exposed male offspring mice declined, as compared with the control group $(\mathrm{P}<0.05$ or $\mathrm{P}<0.01$, Fig. 1C).

Pathological changes in the murine testicular tissue samples, as determined by $\mathrm{HE}$ staining. $\mathrm{HE}$ staining was used to observe pathological changes in the murine testicular tissue samples of the various groups at 6 weeks (Fig. 2). In the control group, normal morphology of the testicular tissue was observed, whereas in the BPA-treated groups, the seminiferous tubules of the testicular tissue and the tube cell wall layers and cells appeared disordered, observations that worsened in a dose-dependent manner.

Protein expression of $\beta$-catenin and DKK-1, as determined by immunohistochemical analysis. The protein expression of $\beta$-catenin and DKK-1 was markedly increased in the BPA-treated groups, as compared with the control group. The expression was increased in a dose-dependent manner, and was predominantly observed in the spermatogenic and Leydig cells (Fig. 3A). As shown in Fig. 3B, the number of $\beta$-catenin and DKK-1 positive cells significantly increased in the BPA-treated groups $(\mathrm{P}<0.01)$, as compared with the solvent control group, as determined by the Nikon 80 I Biological Microscopic Camera and Analysis system.

Effects of BPA on the protein expression levels of $\beta$-catenin and DKK-1 in the testicular tissue samples. To investigate the mechanism underlying the effects of BPA on the Wnt/ $\beta$-catenin signaling pathway, the protein expression levels of $\beta$-catenin and DKK-1 were detected in the testicular tissue samples of the various groups by western blotting (Fig. 4A). Higher protein expression levels of $\beta$-catenin and DKK-1 were detected in the BPA-treated groups, as compared with the control group, and expression was increased in a dose-dependent manner $(\mathrm{P}<0.05$, or $\mathrm{P}<0.01$; Fig. 4B).

\section{Discussion}

BPA is a monomer component of epoxy resins, which are used in numerous food-contact plastics. Over the past decade, numerous studies have reported that BPA acts as a potential EDC $(19,20)$. EDCs or xenoestrogens are able to disrupt endocrine functions by blocking endogenous hormones (21). At present, the hypothesis that BPA acts as an EDC is primarily based on the results of in vitro studies, which have seldom been confirmed in vivo. BPA was chosen to be investigated in the present study due to its presence in resin-based dental sealants and composites, and due to the degradation of BPA in certain resins $(1-3,22)$. Human exposure to similar doses of BPA has also been reported to occur from the consumption of foods preserved in lacquer-coated cans (23). The BPA doses used in the present study were selected according to previous reports on the effects of BPA on the fertility and reproduction of mice exposed to BPA during pregnancy (24-26). Therefore, the long-term effects of xenoestrogens such as BPA on human health requires further investigation in vivo. The present study aimed to investigate the adverse effects of BPA on the fertility and reproduction of adult male mice. The results demonstrated that ingestion of BPA from GD 1 to PND 42 induced adverse effects on male germ cell development. BPA was administered at a dose of $0.5,10$ and $50 \mu \mathrm{g} / \mathrm{kg}$, and no significant effects on murine fertility were observed between the various treatment groups. Compared with the control group, no significant difference was identified in the number of litter mice and the male:female ratio of the BPA-exposed pregnant mice. The testicular coefficient of the male mouse pups was adversely affected following ingestion of BPA xenoestrogen, and the number of pups in the litters of the BPA-treated groups also decreased. A previous study demonstrated that daily sperm production was significantly reduced and the structure of sperm cells underwent significant changes in adult mice treated with BPA (27). The testes carry out two predominant functions: The production of sperm during spermatogenesis, and the synthesis of testosterone and a small amount of estrogen. The presence of normal testicular tissue structure and function is a prerequisite for the maintenance of reproductive capacity. BPA was shown to increase the levels of murine sperm abnormality, and interfere with the growth and development of the sperm by crossing the blood-testis barrier. These effects were enhanced with an increase in exposure time (28). The results of the present study indicated that no significant difference was observed in the male:female ratio of the litters. 
A

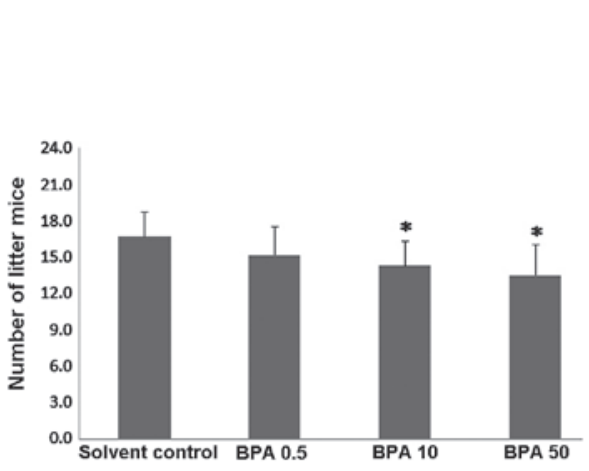

B

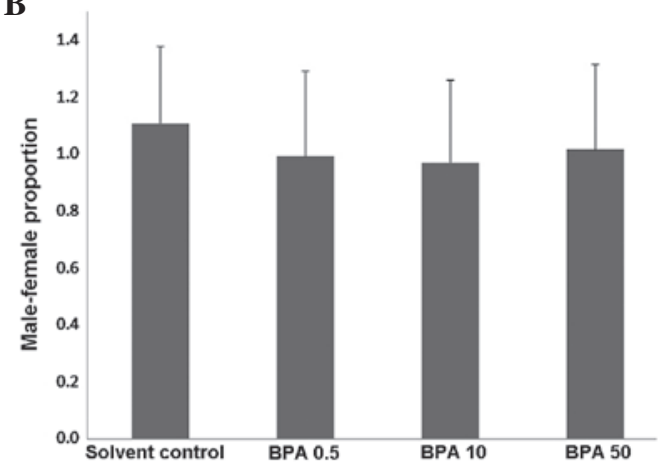

C

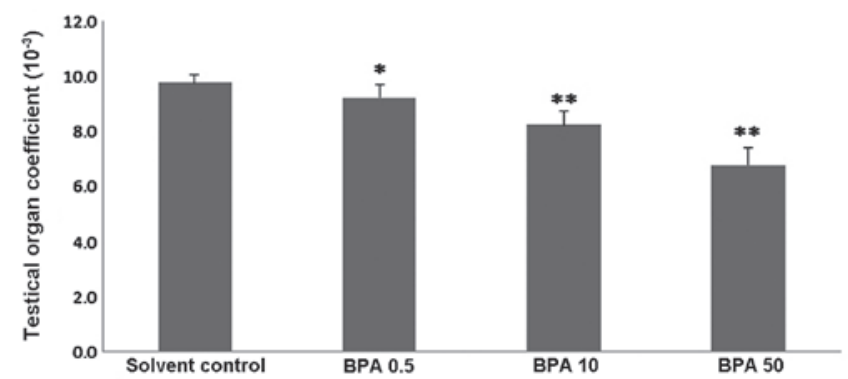

Figure 1. General parameters of reproduction and development. (A) Number of litter mice following treatment with various doses $(\mu \mathrm{g} / \mathrm{kg} / \mathrm{day})$ of bisphenol A (BPA) during pregnancy. (B) Male:female ratio of the offspring of mice exposed to BPA during pregnancy. (C) The testicular viscera coefficient was signficantly decreased in the BPA-exposed male offspring. Data are presented as the mean \pm standard deviation. ${ }^{*} \mathrm{P}<0.05$, and ${ }^{* *} \mathrm{P}<0.01$, vs. the solvent control group.

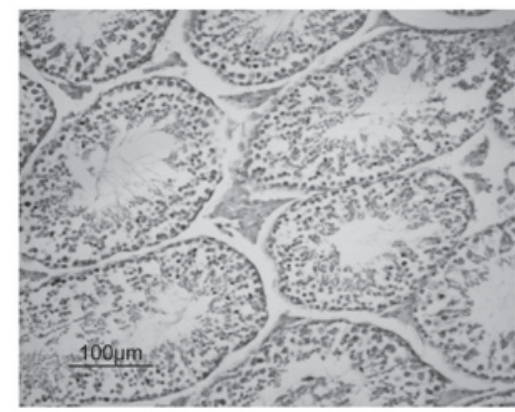

Solvent control group

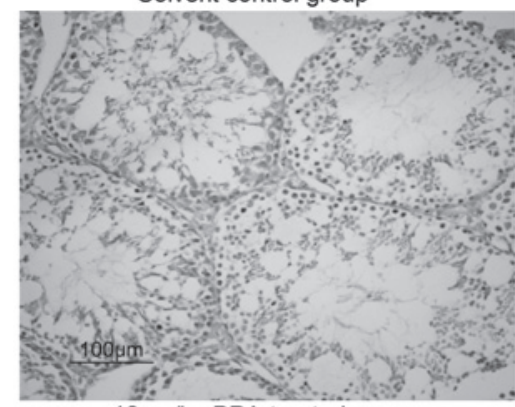

$10 \mu \mathrm{g} / \mathrm{kg}$ BPA-treated group

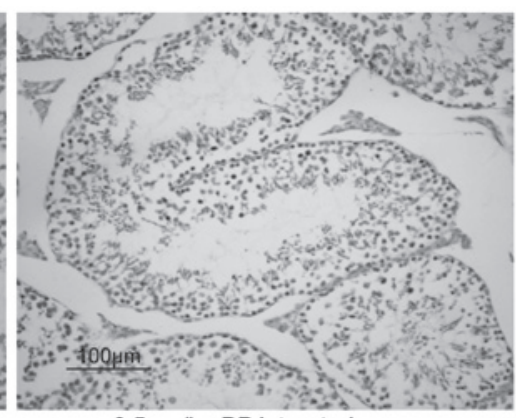

$0.5 \mu \mathrm{g} / \mathrm{kg}$ BPA-treated group

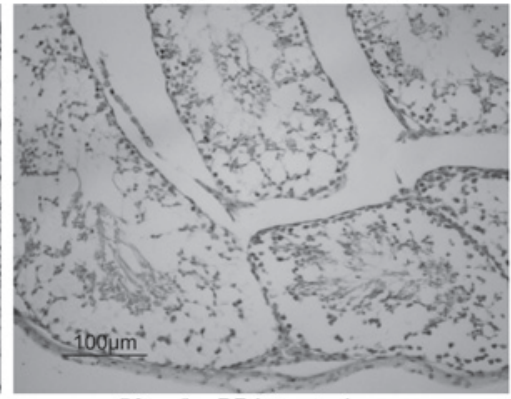

$50 \mu \mathrm{g} / \mathrm{kg}$ BPA-treated group

Figure 2. Hematoxylin and eosin (HE) staining of the testicular tissue samples of the male offspring at postnatal day 42 . The morphology of the seminiferous tubules was normal in the solvent control group. The seminiferous tubules exhibited reduced cell layers, and the cells were disordered in the 0.5 , 10 , and $50 \mu \mathrm{g} / \mathrm{kg} /$ day bisphenol A (BPA) groups, (HE, x200 magnification).

The HE staining results of the present study contradict those of a recent study, which demonstrated that pregnancy rates were significantly reduced in females exposed to high doses of BPA during pregnancy (29). In addition, in the BPA-treated groups, the seminiferous tubules of the testicular tissue and the tube cell wall layers and cells appeared disordered, observations that worsened in a dose-dependent manner. During cell differentiation, BPA alters gene activity levels during sensitive developmental periods, so that the function of BPA-exposed cells are irreversibly disrupted. BPA acts as a long-term EDC, which deregulates the development of testicular germ cells. Although numerous studies have been conducted on BPA, its effects on the reproductive system remain controversial. A previous study demonstrated that treatment with BPA during 
A
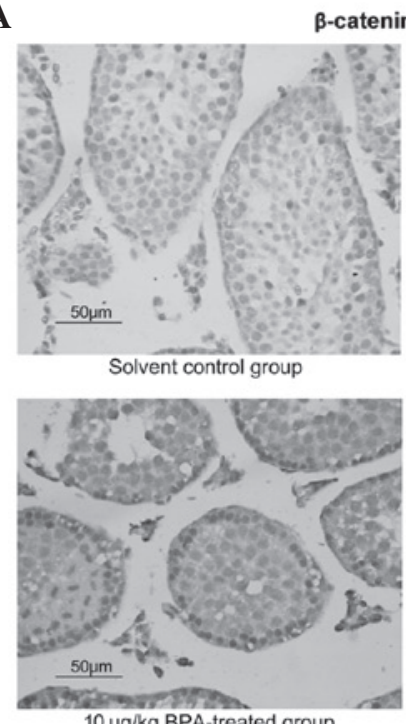

$10 \mu \mathrm{g} / \mathrm{kg}$ BPA-treated group

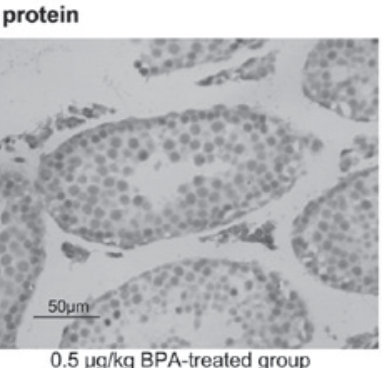

$0.5 \mu \mathrm{g} / \mathrm{kg}$ BPA-treated group

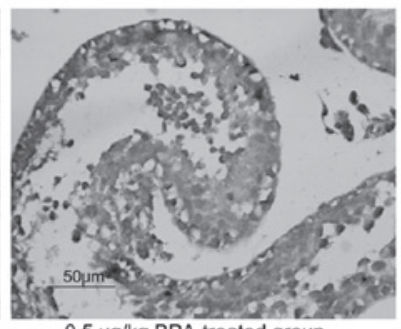

$0.5 \mu \mathrm{g} / \mathrm{kg}$ BPA-treated group

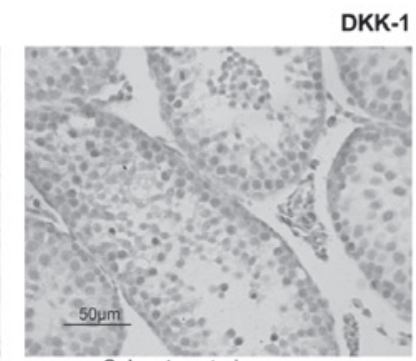

Solvent control group

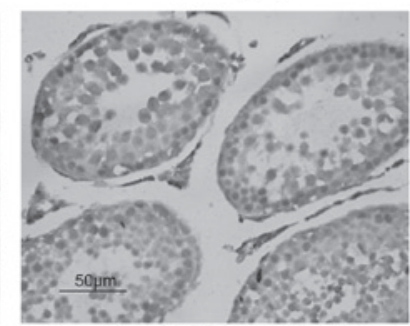

$10 \mu \mathrm{g} / \mathrm{kg}$ BPA-treated group

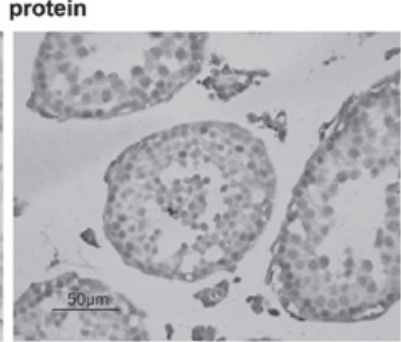

$0.5 \mu \mathrm{g} / \mathrm{kg}$ BPA-treated group

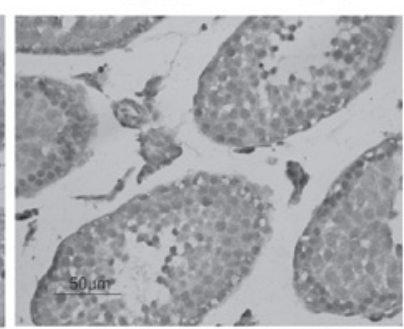

$50 \mu \mathrm{g} / \mathrm{kg}$ BPA-treated group

B

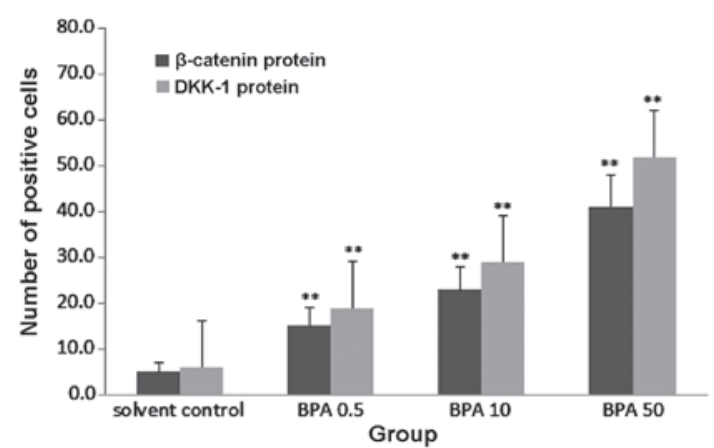

Figure 3. Protein expression levels of $\beta$-catenin and dickkopf WNT signaling pathway inhibitor 1 (DKK-1) in the testicular tissue samples of the various treatment groups. (A) Expression was determined by immunohistochemical staining (magnification, $\mathrm{x} 400$ ). (B) The number of $\beta$-catenin and DKK-1-positive cells. Data are presented as the mean \pm standard devaition. ${ }^{* *} \mathrm{P}<0.01$, vs. the control group. BPA, bisphenol A.

A

\begin{tabular}{|c|c|}
\hline$-\infty-\infty$ & $\beta$-catenin \\
\hline$+\infty \omega \infty$ & DKK-1 \\
\hline$\infty$ & $\beta$-actin \\
\hline
\end{tabular}

\section{B}

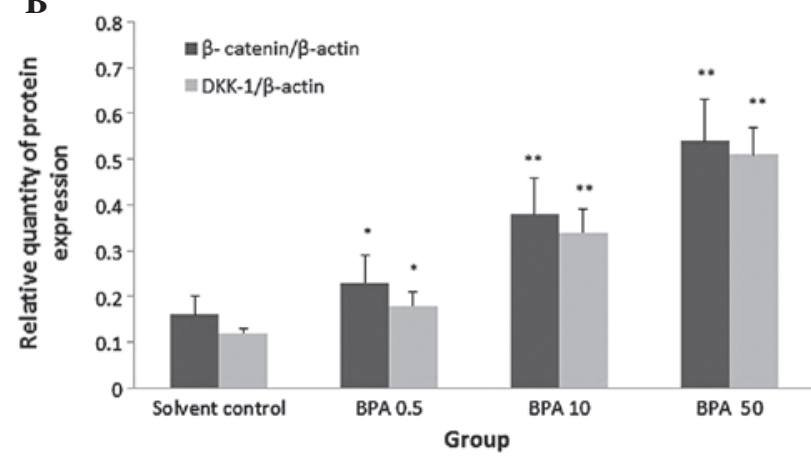

Figure 4. Effects of the various concentrations of bisphenol A (BPA) treatment on the protein expression levels of $\beta$-catenin and dickkopf WNT signaling pathway inhibitor 1 (DKK-1) in the testicular tissue samples of the various groups. (A) The protein expression levels of $\beta$-catenin, DKK-1 and $\beta$-actin as determined by western blotting. (B) The mean protein expression levels of $\beta$-catenin and DKK-1 as quantified by scanning densitometry. Data are presented as the mean \pm standard deviation $(n=6)$. ${ }^{*} \mathrm{P}<0.05$, and ${ }^{* *} \mathrm{P}<0.01$, vs. the control group.

pregnancy exerted effects on the reproductive cells of the male offspring, effects that increased in a dose-dependent manner (30).

The Wnt/ $\beta$-catenin signaling pathway is involved in cell growth and development, predominantly via Wnt, Wnt receptor proteins, $\beta$-catenin, and Tcf/Lef nuclear transcription factors and their downstream target genes (31). The standardized Wnt/ $\beta$-catenin pathway is initiated by the binding of
Wnt to cell surface molecules LRP5/6 and Frizzled (Frz), which induces the release of cytoplasmic $\beta$-catenin from a protein complex composed of Axin1/2, glycogen synthase kinase $3 b$, casein kinase 1 , and adenomatous polyposis coli. $\beta$-catenin subsequently translocates into the cell nucleus by dephosphorylation and release. $\beta$-catenin then interacts with the Tcf/Lef1, which activates the expression of target genes in the nucleus (32). 
Wnt is rich in cysteine residues and contains a highly conserved glycoprotein signal. More than 19 types of Wnt genes have been identified in the genomes of mice and humans (33). Wnt proteins bind to the cell membrane receptor Frz, which causes the cytoplasmic shock protein Dishevelled to inhibit the $\beta$-catenin degradation pathway; $\beta$-catenin then relocates from the cytoplasm into the cell nucleus, where it acts as the downstream transcriptional activator of the Wnt signaling pathway, via binding with Tcf/Lef nuclear sites, which induces the activation of downstream target gene transcription (34). Previous studies have also shown that DKK-1 has an important role in the Wnt signaling pathway, and is involved in embryonic development $(35,36)$. The present study investigated the mechanism underlying Wnt signaling, and the association between Wnt signaling and testis development in male mice. The results of the present study demonstrated that the protein expression levels of $\beta$-catenin and DKK-1 were significantly increased in the BPA-treated groups, as compared with the control group, as determined by immunohistochemical analyses and cell counting. These upregulated expression levels further increased with BPA treatment, and were predominantly observed in the spermatogenic and Leydig cells. However, the mechanism underlying the Wnt/ $\beta$-catenin signaling pathway and its association with BPA-induced inhibition of male mouse reproductive cell growth and development remains to be further elucidated.

The majority of the downstream target genes of the Wnt/ $\beta$-catenin signaling pathways are involved in cell cycle regulation, and cell proliferation, differentiation, and apoptosis, which are important for numerous embryonic developmental events, including the formation of the embryonic axis an abdomen, and the establishment of cell polarity and cell fate (37). If the Wnt signaling pathway is inhibited, embryonic development will gradually be disrupted resulting in mutated phenotypes, such as the Wnt 3 mutation that causes head deformities, or lack of (short) limb deformities (38). In addition, a previous study demonstrated that induction of the downstream components of the Wnt/ $\beta$-catenin signaling pathway, including inhibitor of bone morphology proteins and DKK-1 proteins, induces cell apoptosis, which in turn leads to birth defects (39). The results of the present study demonstrated that the protein expression levels of $\beta$-catenin and DKK-1 were markedly increased following BPA treatment, in a dose-dependent manner, as compared with the control group.

In conclusion, treatment of ICR pregnant mice with BPA resulted in structural changes in the spermatogenic and Leydig cells of male offspring. In addition, investigation of the Wnt/ $\beta$-catenin signaling pathway, which regulates the development of male murine reproductive cells, suggested that BPA may pass through the placental barrier, affecting the development of endogenous testicular sperm cells; however, the mechanism underlying the effects of BPA requires further research.

\section{Acknowledgements}

The present study was supported by grants from the National Natural Science Foundation of China (grant no. 81373421), and the Innovative Entrepreneurial Training of the National College Students' Program (grant no. 201310366007). The authors are grateful to Dr Tong Shen (Toxicology Experimental Center of the Drug Research Office in Anhui Medical University, China) for contributions to animal experiments.

\section{References}

1. Yamamoto T, Yasuhara A, Shiraishi $H$ and Nakasugi O: Bisphenol A in hazardous waste landfill leachates. Chemosphere 42: 415-418, 2001.

2. Ikezuki Y, Tsutsumi O, Takai Y, Kamei Y and Taketani Y: Determination of bisphenol A concentrations in human biological fluids reveals significant early prenatal exposure. Hum Reprod 17: 2839-2841, 2002.

3. Vandenberg LN, Hauser $\mathrm{R}$, Marcus $\mathrm{M}$, Olea $\mathrm{N}$ and Welshons WV: Human exposure to bisphenol A (BPA). Reprod Toxicol 24: 139-177, 2007.

4. Michałowicz J: Bisphenol A - sources, toxicity and biotransformation. Environ Toxicol Pharmacol 37: 738-758, 2014.

5. Ouchi K and Watanabe S: Measurement of bisphenol A in human urine using liquid chromatography with multi-channel coulometric electrochemical detection. J Chromatogr B Analyt Technol Biomed Life Sci 780: 365-370, 2002.

6. Pupo M, Pisano A, Lappano R, Santolla MF, De Francesco EM, Abonante S, Rosano C and Maggiolini M: Bisphenol A induces gene expression changes and proliferative effects through GPER in breast cancer cells and cancer-associated fibroblasts. Environ Health Perspect 120: 1177-1182, 2012.

7. Mattsson A, Mura E, Brunström B, Panzica G and Halldin K: Selective activation of estrogen receptor alpha in Japanese quail embryos affects reproductive organ differentiation but not the male sexual behavior or the parvocellular vasotocin system. Gen Comp Endocrinol 159: 150-157, 2008.

8. Calafat AM, YeX, Wong LY, Reidy JA and Needham LL: Exposure of the U.S. population to bisphenol A and 4-tertiary-octylphenol: 2003-2004. Environ Health Perspect 116: 39-44, 2008.

9. Nagel SC, vom Saal FS, Thayer KA, Dhar MG, Boechler M and Welshons WV: Relative binding affinity-serum modified access (RBA-SMA) assay predicts the relative in vivo bioactivity of the xenoestrogens bisphenol A and octylphenol. Environ Health Perspect 105: 70-76, 1997.

10. Khan SA, Ball RB and Hendry WJ III: Effects of neonatal administration of diethylstilbestrol in male hamsters: Disruption of reproductive function in adults after apparently normal pubertal development. Biol Reprod 58: 137-142, 1998.

11. Nagao T, Saito Y, Usumi K, Nakagomi M, Yoshimura S and Ono H: Disruption of the reproductive system and reproductive performance by administration of nonylphenol to newborn rats. Hum Exp Toxicol 19: 284-296, 2000.

12. McKinnell C, Atanassova N, Williams K, Fisher JS, Walker M, Turner KJ, Saunders TK and Sharpe RM: Suppression of androgen action and the induction of gross abnormalities of the reproductive tract in male rats treated neonatally with diethylstilbestrol. J Androl 22: 323-338, 2001.

13. Atanassova N, McKinnell C, Walker M, Turner KJ, Fisher JS Morley M, Millar MR, Groome NP and Sharpe RM: Permanent effects of neonatal estrogen exposure in rats on reproductive hormone levels, Sertoli cell number, and the efficiency of spermatogenesis in adulthood. Endocrinology 140: 5364-5373, 1999.

14. Kabuto H, Amakawa $M$ and Shishibori T: Exposure to bisphenol A during embryonic/fetal life and infancy increases oxidative injury and causes underdevelopment of the brain and testis in mice. Life Sci 74: 2931-2940, 2004.

15. Taylor JA, Richter CA, Ruhlen RL and vom Saal FS: Estrogenic environmental chemicals and drugs: Mechanisms for effects on the developing male urogenital system. J Steroid Biochem Mol Biol 127: 83-95, 2011.

16. Klapholz-Brown Z, Walmsley GG, Nusse YM, Nusse R and Brown PO: Transcriptional program induced by Wnt protein in human fibroblasts suggests mechanisms for cell cooperativity in defining tissue microenvironments. PLoS One 2: e945, 2007.

17. Hu T and Li C: Convergence between Wnt- $\beta$-catenin and EGFR signaling in cancer. Mol Cancer 9: 236, 2010.

18. Rexhepaj E, Agnarsdóttir M,Bergman J,Edqvist PH,Bergqvist M, Uhlén M, Gallagher WM, Lundberg E and Ponten F: A texture based pattern recognition approach to distinguish melanoma from non-melanoma cells in histopathological tissue microarray sections. PLoS One 8: e62070, 2013. 
19. Barrett ES and Sobolewski M: Polycystic ovary syndrome: Do endocrine-disrupting chemicals play a role? Semin Reprod Med 32: 166-176, 2014.

20. Rochefort H: Bisphenol A and hormone-dependent cancers: Potential risk and mechanism. Med Sci 29: 539-544, 2013.

21. Lee HR, Jeung EB, Cho MH, Kim TH, Leung PC and Choi KC: Molecular mechanism(s) of endocrine-disrupting chemicals and their potent oestrogenicity in diverse cells and tissues that express oestrogen receptors. J Cell Mol Med 17: 1-11, 2013.

22. Bonefeld-Jørgensen EC, Ghisari M, Wielsøe M, Bjerregaard-Olesen $\mathrm{C}$, Kjeldsen LS and Long M: Biomonitoring and hormone-disrupting effect biomarkers of persistent organic pollutants in vitro and ex vivo. Basic Clin Pharmacol Toxicol 115: 118-128, 2014.

23. Sultan C, Balaguer P, Terouanne B, Georget V, Paris F, Jeandel C, Lumbroso S and Nicolas J: Environmental xenoestrogens, antiandrogens and disorders of male sexual differentiation. Mol Cell Endocrinol 178: 99-105, 2001.

24. Nagel SC, vom Saal FS, Thayer KA, Dhar MG, Boechler M and Welshons WV: Relative binding affinity-serum modified access (RBA-SMA) assay predicts the relative in vivo bioactivity of the xenoestrogens bisphenol A and octylphenol. Environ Health Perspect 105: 70-76, 1997.

25. vom Saal FS, Cooke PS, Buchanan DL, Palanza P, Thayer KA, Nagel SC, Parmigiani S and Welshons WV: A physiologically based approach to the study of bisphenol A and other estrogenic chemicals on the size of reproductive organs, daily sperm production, and behavior. Toxicol Ind Health 14: 239-260, 1998.

26. Gupta C: Reproductive malformation of the male offspring following maternal exposure to estrogenic chemicals. Proc Soc Exp Biol Med 224: 61-68, 2000.

27. Toyama Y, Suzuki-Toyota F, Maekawa M, Ito C and Toshimori K: Adverse effects of bisphenol A to spermiogenesis in mice and rats. Arch Histol Cytol 67: 373-381, 2004

28. Minamiyama Y, Ichikawa H, Takemura S, Kusunoki H, Naito Y and Yoshikawa T: Generation of reactive oxygen species in sperms of rats as an earlier marker for evaluating the toxicity of endocrine-disrupting chemicals. Free Radic Res 44: 1398-1406, 2010.

29. Yan PP, Pan XY, Wang HH, Li ZX, Wang XN, Lai Q, Song WJ, Zhao HY and Dou ZH: Effects of bisphenol-A on blastocyst development and implantation. Zhongguo Yi Xue Ke Xue Yuan Xue Bao 36: 351-356, 2014.
30. Liu XL, Chen XY, Wang ZC, Shen T and Zhao H: Effects of exposure to bisphenol A during pregnancy and lactation on the testicular morphology and caspase-3 protein expression of ICR pups. Biomed Rep 1: 420-424, 2013.

31. Logan CY and Nusse R: The Wnt signaling pathway in development and disease. Annu Rev Cell Dev Biol 20: 781-810, 2004.

32. Wang Q, Cai J, Cai XH and Chen L: miR-346 regulates osteogenic differentiation of human bone marrow-derived mesenchymal stem cells by targeting the Wnt/ $\beta$-catenin pathway. PLoS One 8: e72266, 2013.

33. Fujimaki S, Hidaka R, Asashima M, Takemasa $T$ and Kuwabara T: Wnt protein-mediated satellite cell conversion in adult and aged mice following voluntary wheel running. J Biol Chem 289: 7399-7412, 2014.

34. Zhang X, Li M, Zuo K, Li D, Ye M, Ding L, Cai H, Fu D, Fan Y and Lv Z: Upregulated miR-155 in papillary thyroid carcinoma promotes tumor growth by targeting APC and activating Wnt $/ \beta$-catenin signaling. J Clin Endocrinol Metab 98: E1305-E1313, 2013.

35. Ye S, Wang J, Yang S, Xu W, Xie M, Han K, Zhang B and Wu Z: Specific inhibitory protein Dkk-1 blocking Wnt/ $\beta$-catenin signaling pathway improve protective effect on the extracellular matrix. J Huazhong Univ Sci Technolog Med Sci 31: 657-662, 2011.

36. Kong XB and Zhang C: Dickkopf (Dkk) 1 promotes the differentiation of mouse embryonic stem cells toward neuroectoderm. In Vitro Cell Dev Biol Anim 45: 185-193, 2009.

37. Esteve P, Sandonìs A, Ibañez C, Shimono A, Guerrero I and Bovolenta P: Secreted frizzled-related proteins are required for Wnt $/ \beta$-catenin signalling activation in the vertebrate optic cup. Development 138: 4179-4184, 2011.

38. Knobloch J, Schmitz I, Götz K, Schulze-Osthoff K and Rüther U: Thalidomide induces limb anomalies by PTEN stabilization, Akt suppression, and stimulation of caspase-dependent cell death. Mol Cell Biol 28: 529-538, 2008.

39. Ning B, Wang P, Pei X, Kang Y, Song J, Wang D, Zhang W and Ma R: Dual function of $\beta$-catenin in articular cartilage growth and degeneration at different stages of postnatal cartilage development. Int Orthop 36: 655-664, 2012. 